\title{
The Reovirus M1 Gene Determines the Relative Capacity of Growth of Reovirus in Cultured Bovine Aortic Endothelial Cells
}

\author{
Yoshiki Matoba, ${ }^{\star *}$ Wilson S. Colucci, ${ }^{*}$ Bernard N. Fields, ${ }^{\star 8} \|$ and Thomas W. Smith ${ }^{\star}$ \\ ${ }^{*}$ Cardiovascular Division, Departments of Medicine, Brigham and Women's Hospital, and Harvard Medical School, ${ }^{\ddagger}$ Department \\ of Microbiology and Molecular Genetics, Harvard Medical School, $\$$ Department of Medicine (Infectious Disease), \\ Brigham and Women's Hospital; and "Shipley Institute of Medicine, Boston, Massachusetts 02115
}

\begin{abstract}
Since blood-borne viruses often interact with endothelial cells before tissue invasion, the interaction between viruses and endothelial cells is likely to be important in viral pathogenicity. Two reovirus isolates (type 1 Lang and type 3 Dearing) differ in their capacity to grow in cultured bovine aortic endothelial cells. The mammalian reoviruses have 10 double-stranded RNA gene segments in their genome. By using 24 reassortant viruses, observed differences in the capacity of different strains to grow in cultured endothelial cells were mapped to the M1 gene $(P=0.00019)$, which encodes the viral core protein $\mu 2$. No differences were detected in binding or proteolytic processing of viral outer capsid proteins of parental virions between the two reovirus isolates. Northern blot analysis showed a decreased production of viral mRNA in endothelial cells infected with type 3 Dearing reovirus, but not type 1 Lang. Thus, we have identified a viral gene (the $M 1$ gene) responsible for determining the difference in growth capacity of the two reovirus isolates in cultured endothelial cells. Reovirus is an attractive model in which to study the interaction of viruses with endothelial cells at a molecular genetic level. (J. Clin. Invest. 1993. 92:2883-2888.) Key words: viral pathogenesis • myocarditis • viral mRNA
\end{abstract}

\section{Introduction}

Endothelial cells may play a major role in determining viral pathogenesis. First, since endothelial cells line the luminal surface of blood vessels, to enter tissues blood-borne viruses must first interact with and cross the endothelial barrier. Second, some viruses are known to replicate in endothelial cells, thereby altering cell functions (1).

Reoviruses have a genome composed of 10 doublestranded RNA segments. Because of the segmented nature of the genome, it is possible to produce reassortant viruses containing different combinations of gene segments derived from parental viruses by co-infection of cells (2). Many natural isolates of the three serotypes of reoviruses exist and exhibit different biological properties. By analysis of reassortant viruses generated by mixed infections with two different isolates from

Address correspondence to Dr. Thomas W. Smith, Cardiovascular Division, Brigham and Women's Hospital, 75 Francis Street, Boston, MA 02115.

Received for publication 4 January 1993 and in revised form 19 July 1993.

J. Clin. Invest.

(C) The American Society for Clinical Investigation, Inc.

$0021-9738 / 93 / 12 / 2883 / 06 \quad \$ 2.00$

Volume 92, December 1993, 2883-2888 these serotypes, it has been possible to identify the gene segments responsible for a number of these biological differences (for reviews, see references 3 and 4).

In this report, we used this genetic approach to show that the $M 1$ viral gene encoding the $\mu 2$ viral core protein is responsible for the differing growth capacity of reoviruses (type 1 Lang [T1L], which grows to a high titer, and type 3 Dearing [T3D], which grows poorly) in cultured endothelial cells. A characterization of the T1L and T3D strains studied indicated that these isolates do not differ with regard to cell binding, or uncoating processing. However, the production of viral mRNA in the cells infected by T3D is markedly decreased. Earlier studies have shown that the Ml gene is associated with the differing growth capacity of reoviruses in heart cells in vitro (5) and the induction of myocarditis in vivo (6). Thus, these findings indicate that the M1 gene may play a more general role in determining the capacity of reovirus to grow in differentiated tissues.

\section{Methods}

Viruses and L cells. Mouse L929 (L) cells used for propagation and titration of reoviruses were grown in suspension in the Joklik modification of Eagle's minimal essential medium (MEM) supplemented with 2.5\% FCS (Hyclone Laboratories, Logan, UT) and $2.5 \%$ viable serum protein, as described previously (7). Reovirus serotypes T1L and T3D were from laboratory stocks $(8)$, and the reassortant viruses used in this study (EB series) were prepared as described by Brown et al. (9).

Cultured endothelial cells. Cultured bovine aortic endothelial cells (BAECs)' and human umbilical vein endothelial cells (HUVECs) were generously provided by Michael A. Gimbrone, Jr. (Department of Pathology, Brigham and Women's Hospital, Boston, MA) and have been characterized previously $(10,11)$. BAECs were serially passaged in DME (Gibco Laboratories, Grand Island, NY) supplemented with $10 \% \mathrm{FCS}$ and antibiotics ( $100 \mathrm{U} / \mathrm{ml}$ of penicillin, $100 \mu \mathrm{g} / \mathrm{ml}$ of streptomycin ). Cells from passages 10-20 were used in this study. HUVECs were serially passaged in Medium 199 (M.A. Bioproducts, Bethesda, MD) supplemented with $20 \% \mathrm{FCS}, 50 \mu \mathrm{g} / \mathrm{ml}$ of endothelial cell growth factor (Biomedical Technologies, Inc., Stoughton, MA), $100 \mu \mathrm{g} / \mathrm{ml}$ of heparin (Sigma Chemical Co., St. Louis, MO), and antibiotics (100 $\mathrm{U} / \mathrm{ml}$ of penicillin, $100 \mu \mathrm{g} / \mathrm{ml}$ of streptomycin). Cells from passage three were used in this study.

Infection of endothelial cells. $2 \mathrm{~d}$ after endothelial cells were plated in 24-well clusters, two wells were trypsinized, and viable cells were counted by the trypan blue exclusion method. Cells $\left(0.8 \times 10^{5}-1.6\right.$ $\times 10^{5}$ cells/well) were infected at a multiplicity of infection (MOI) of three and incubated for 90 min with intermittent rocking. Cells were then washed three times, and DME with $1 \%$ FCS (for BAECs) or M 199 with $10 \%$ FCS (for HUVECs) were added. Infection was terminated by freezing the clusters on the day indicated in Fig. 1 (day 0-4).

1. Abbreviations used in this paper: BAECs, bovine aortic endothelial cells; HSV-1, herpes simplex virus 1; HUVECs, human umbilical vein endothelial cells; PFU, plaque-forming units. 
Viral titer determination. Cells in 24-well clusters were frozen $\left(-70^{\circ} \mathrm{C}\right)$ and thawed $\left(37^{\circ} \mathrm{C}\right)$ three times and disrupted by sonication (7). The viral suspensions were serially diluted in 10-fold steps in gel saline and plated in duplicate on L-cell monolayers for plaque assays as described previously (12). Viral titers were expressed as plaque-forming units (PFU) per cell.

Radiolabeling of the virus. Radiolabeled viruses were prepared as previously described (13) by infection (at an MOI of 10 ) of L cells $(2.5$ $\times 10^{8}$ cells $)$ with $700 \mu \mathrm{Ci}$ of $\left[{ }^{35} \mathrm{~S}\right]$ methionine $(\sim 1,100 \mathrm{Ci} / \mathrm{mmol} ; \mathrm{ICN}$ Biomedicals, Irvine, CA), and were purified on equilibrium $\mathrm{CsCl}_{2}$ gradients after trichlorotrifluoroethane (Freon) extraction, as previously described (14). The specific radioactivity of viruses ranged from 1.2 $\times 10^{5}-3.8 \times 10^{5}$ particles $/ \mathrm{cpm}\left(1.7 \times 10^{13}-5.2 \times 10^{13}\right.$ particles $\left./ \mathrm{ml}\right)$.

Virus binding assay. BAECs were plated in six-well clusters (1.2 $\times 10^{6}$ cells/well) in $2.5 \mathrm{ml}$ of DME and $10 \%$ FCS. The next day, the medium was decanted, and the plates were chilled on ice for 10-20 min. ${ }^{35} \mathrm{~S}$-Radiolabeled viruses were added at an $\mathrm{MOI}$ of 100 to achieve $10^{4}$ particles/cell ( the ratio of particle to PFU was supposed to be 100 [3]). Viral attachment was allowed to proceed at $4^{\circ} \mathrm{C}$ with intermittent rocking and was terminated by washing the clusters with cold PBS five times at the time indicated in Fig. 2(0-120 min). Trypsin (0.05\%) was added to detach the cell monolayers from the plates, and the radioactivity of cell-bound viruses was counted with a Rackbeta liquid scintillation counter (LKB, Turku, Finland). The percentage of binding was calculated by comparing the radioactivity of cell-bound viruses with that of total viruses (inoculum) added to the wells $\left(1.5 \times 10^{5}-2.0 \times 10^{5}\right.$ $\mathrm{cpm} /$ well).

Proteolytic processing of viral proteins. BAECs were plated in 100$\mathrm{mm}$ dishes $\left(6.0 \times 10^{6}\right.$ cells/dish $)$ in $12 \mathrm{ml}$ of DME and $10 \%$ FCS. The next day, ${ }^{35} \mathrm{~S}$-radiolabeled virus was added as described for the binding assay. After unbound inoculum was removed by washing, cells were overlaid with DME at $37^{\circ} \mathrm{C}$ for the period indicated in Fig. 3(0-6 hr). Later steps for preparation of viral proteins and analysis of their proteolytic processing with use of sodium dodecyl sulfate-polyacrylamide gel electrophoresis (SDS-PAGE) were as described (13), except that a longer incubation period ( $30 \mathrm{~min}$ ) was used for lysis of the cells.

Northern blot analysis. Cells (BAECs or L cells) were plated on 100-mm dishes, and after confluence was reached, a dish was trypsinized and viable cells were counted by the trypan blue exclusion method $\left(0.5 \times 10^{7}-1.0 \times 10^{7}\right.$ cells $/$ dish $)$. Cells were infected at an MOI of 10 and incubated for $90 \mathrm{~min}$ with intermittent rocking. The cells were then washed three times, and DME with $1 \%$ FCS was added. Preparation of RNA and Northern blot analysis were done by standard methods. Total RNA was extracted from cultured cells by the guanidinium isothiocyanate $/ \mathrm{CsCl}_{2}$ method (15), and $100-150 \mu \mathrm{g}$ of RNA was usually obtained from two dishes. Total RNA ( $10 \mu \mathrm{g} /$ lane $)$ was denatured with formaldehyde and formamide, size-fractionated in a $1.3 \%$ agarose/1.5\% formaldehyde gel, transferred to a GeneScreen Plus membrane (DuPont, Boston, MA), and fixed by baking in a vacuum oven at $80^{\circ} \mathrm{C}$ for $2 \mathrm{~h}$. A full-length cDNA probe for the $\mathrm{S} 4$ gene of

Table I. Reovirus Reassortants Used to Map the Ability of Reovirus to Grow in Cultured Endothelial Cells

\begin{tabular}{|c|c|c|c|c|c|c|c|c|c|c|c|c|}
\hline \multirow[b]{2}{*}{ Virus } & \multicolumn{10}{|c|}{ Origin of gene segment encoding } & \multirow[b]{2}{*}{ Viral yield } & \multirow[b]{2}{*}{ Rank } \\
\hline & $\mathrm{L} 1$ & L2 & L3 & M1 & S2 & S1 & M2 & S4 & M3 & S3 & & \\
\hline & & & & & & & & & & & PFU/cell & \\
\hline EB 136 & 3 & 3 & 3 & 1 & 3 & 3 & 3 & 3 & 1 & 3 & $125 \pm 14$ & 24 \\
\hline EB 68 & 1 & 3 & 1 & 1 & 1 & 1 & 3 & 3 & 1 & 3 & $119 \pm 10$ & 22 \\
\hline EB 15 & 3 & 3 & 1 & 1 & 3 & 1 & 1 & 3 & 3 & 1 & $119 \pm 5$ & 22 \\
\hline EB 47 & 1 & 3 & 1 & 1 & 1 & 1 & 1 & 1 & 1 & 1 & $119 \pm 18$ & 22 \\
\hline EB 74 & 1 & 3 & 1 & 1 & 1 & 1 & 1 & 1 & 1 & 3 & $106 \pm 19$ & 20 \\
\hline EB 143 & 3 & 1 & 1 & 1 & 1 & 3 & 1 & 1 & 1 & 1 & $103 \pm 16$ & 19 \\
\hline EB 39 & 1 & 3 & 3 & 1 & 3 & 3 & 3 & 3 & 3 & 3 & $90 \pm 11$ & 18 \\
\hline EB 140 & 3 & 3 & 1 & 1 & 1 & 1 & 1 & 1 & 1 & 3 & $87 \pm 11$ & 17 \\
\hline $\mathrm{T} 1 \mathrm{~L}$ & 1 & 1 & 1 & 1 & 1 & 1 & 1 & 1 & 1 & 1 & $75 \pm 5$ & \\
\hline EB 144 & 1 & 1 & 1 & 1 & 1 & 1 & 3 & 1 & 3 & 3 & $73 \pm 24$ & 16 \\
\hline EB 98 & 1 & 3 & 1 & 1 & 3 & 1 & 1 & 3 & 1 & 1 & $69 \pm 22$ & 15 \\
\hline EB 1 & 1 & 3 & 1 & 1 & 1 & 1 & 3 & 1 & 1 & 3 & $48 \pm 12$ & 14 \\
\hline EB 108 & 1 & 3 & 1 & 3 & 1 & 1 & 1 & 3 & 1 & 3 & $47 \pm 8$ & 13 \\
\hline EB 138 & 3 & 1 & 1 & 3 & 3 & 3 & 3 & 1 & 1 & 1 & $43 \pm 16$ & 11.5 \\
\hline EB 146 & 1 & 1 & 1 & 3 & 1 & 1 & 1 & 3 & 1 & 1 & $43 \pm 8$ & 11.5 \\
\hline EB 127 & 3 & 3 & 1 & 1 & 3 & 1 & 3 & 1 & 1 & 3 & $17 \pm 1$ & 10 \\
\hline EB 132 & 3 & 3 & 1 & 3 & 3 & 3 & 3 & 1 & 1 & 3 & $12 \pm 2$ & 9 \\
\hline EB 120 & 3 & 3 & 3 & 1 & 3 & 3 & 1 & 1 & 3 & 1 & $11 \pm 3$ & 8 \\
\hline EB 113 & 1 & 1 & 1 & 3 & 1 & 1 & 1 & 1 & 1 & 3 & $10 \pm 3$ & 7 \\
\hline EB 121 & 3 & 3 & 1 & 3 & 3 & 1 & 1 & 3 & 3 & 3 & $7 \pm 1$ & 6 \\
\hline EB 96 & 1 & 3 & 1 & 3 & 1 & 1 & 1 & 1 & 1 & 3 & $6 \pm 1$ & 5 \\
\hline EB 128 & 3 & 3 & 1 & 3 & 3 & 1 & 3 & 1 & 3 & 3 & $3 \pm 1$ & 4 \\
\hline EB 18 & 3 & 3 & 1 & 3 & 1 & 1 & 3 & 1 & 3 & 3 & $2 \pm 0$ & 3 \\
\hline EB 88 & 3 & 3 & 3 & 3 & 3 & 3 & 1 & 3 & 3 & 3 & $1 \pm 0$ & 1.5 \\
\hline EB 86 & 1 & 3 & 3 & 3 & 3 & 3 & 3 & 1 & 1 & 3 & $1 \pm 0$ & 1.5 \\
\hline T3D & 3 & 3 & 3 & 3 & 3 & 3 & 3 & 3 & 3 & 3 & $0 \pm 0$ & \\
\hline
\end{tabular}

24 Reassortant viruses were used for this study, and gene segments from type 1 Lang (T1L) and type 3 Dearing (T3D) are designated 1 and 3 , respectively. Viral yields are expressed as mean \pm SD from three wells. The data from T1L and T3D are not included for the rank, because these viruses are the parents of the other viruses and have different backgrounds. 
reovirus type 3 was generously supplied by Michael Giantini (Roche Research Center, Nutley, NJ) (16). ${ }^{32}$ P-Labeled probe $\left(6-9 \times 10^{7}\right.$ $\mathrm{cpm} /$ hybridization) was prepared by the random hexamer priming method (17), and hybridized to blots overnight at $42^{\circ} \mathrm{C}$ as described (18). Hybridized blots were washed and autoradiographed on Kodak XAR film with an intensifying screen at $-70^{\circ} \mathrm{C}$ overnight. The same blots were hybridized with ${ }^{32} \mathrm{P}$-labeled cDNA for $18 \mathrm{~S}$ ribosomal RNA (18) to confirm equal loading and/or transfer efficiencies.

Statistical analysis. The Wilcoxon rank sum analysis (19) was applied to examine the relative contribution of each reovirus gene segment to viral growth in cultured endothelial cells. Reassortant viruses in Table I were ordered by viral yields and then assigned a rank consistent with this order. In each gene segment, ranks were summed up separately according to whether the gene segment was derived from T1L or from T3D. When the sum of ranks fell outside the limits at a given value in the table, the next highest $P$ value was examined, until the $P$ value identified within the sum of ranks fell.

\section{Results}

Growth of reovirus in cultured endothelial cells. In BAECs inoculated with $\mathrm{T} 1 \mathrm{~L}$ reovirus, there was progressive viral replication approaching a plateau of $\sim 80 \mathrm{PFU} /$ cell on day 4 . In contrast, T3D showed no growth over the same period (Fig. 1 $A$ ). To confirm whether the observed difference in reovirus replication was specific to BAECs or would be observed in other cultured endothelial cells, growth of reovirus was also examined in HUVECs, a well-characterized endothelial cell of human origin. T1L also replicated well (and actually more
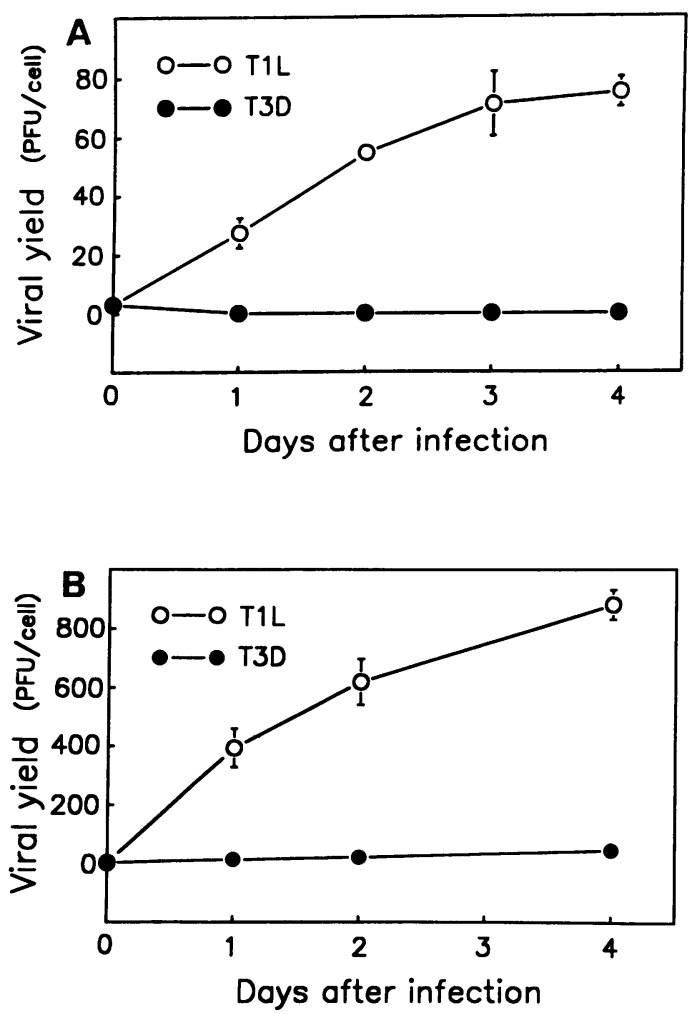

Figure 1. Growth of reovirus (type 1 Lang [T1L] and type 3 Dearing [T3D]) in cultured BAECs $(A)$ and $\operatorname{HUVECs}(B)$. Cells were infected (at a multiplicity of infection of 3 ) $2 \mathrm{~d}$ after plating (day 0 ) and were frozen on the day indicated. Viral yields were determined by plaque assay as described in Methods, and are expressed as mean \pm SD from three wells. than in BAECs) in HUVECs, and T3D did not (Fig. $1 B$ ). Thus, the differing growth capacity of the two strains of reovirus observed in BAECs may be general findings in endothelial cells.

Mapping of the viral gene responsible for different growth capacity of reovirus $T 1 L$ and T3D using reassortant viruses. To identify the genes responsible for the differing growth capacity of the two strains, reassortants of these parental viruses (EB series) were tested for their capacity to grow in BAECs. We chose $4 \mathrm{~d}$ after infection in order to maximize the difference of growth between the two parental viruses. The results of the growth experiments are shown in Table I. The 24 reassortant viruses are placed in order of their yields, the highest being listed first. T1L and T3D are included for reference. The viral yield of T1L was among the highest and that of T3D was the lowest of all viruses tested. The viral yield of the reassortants formed a continuum, and it was difficult to draw a clear boundary between higher and lower yields. Accordingly, we applied a Wilcoxon rank sum analysis (19) as we had in previous studies (5). The only gene that had statistical significance was the M1 gene $(P=0.00019)$; the other nine genes were not related ( $P$ $>0.1)$ to the differing growth capacity of the reoviral reassortants in BAECs. It is of note that EB 136 and EB 39 contained only two genes (one of which was the M1 gene) derived from T1L, and still grew to higher titers (Table I).

Binding of reovirus to cultured bovine aortic endothelial cells. To analyze at which stage (s) in the reovirus replication cycle (3) the M1 gene determines the different growth capacity of reoviruses in BAECs, we performed binding assays, SDSPAGE analysis of proteolytic processing of viral proteins, and Northern blot analysis. We first examined the binding of radiolabeled T1L and T3D to BAECs. The two viruses (T1L and T3D) bound almost equally to these cells, indicating that difference in binding does not account for the difference in growth (Fig. 2).

Proteolytic processing of viral proteins in cultured bovine aortic endothelial cells. Reoviruses enter the cells and are uncoated inside vesicles (endosomes/lysosomes) before activation of the viral transcriptase and production of mRNA occur. Reovirus uncoating involves proteolytic digestion of the viral outer capsid proteins ( $\sigma 3$ and $\mu 1 \mathrm{c}$ ). The typical pattern of in-

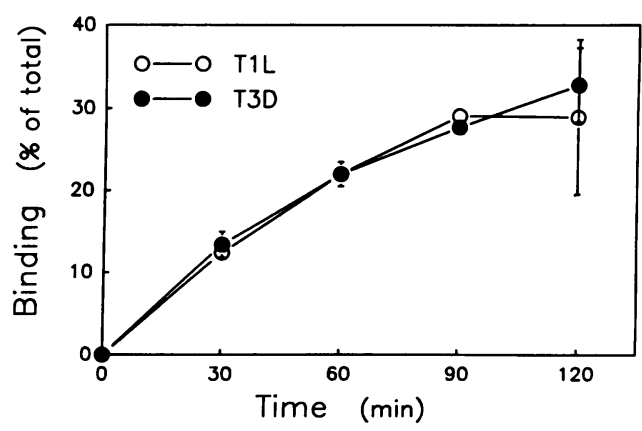

Figure 2. Binding of reovirus (type 1 Lang [T1L] and type 3 Dearing [T3D]) to cultured BAECs. Cells in six-well clusters $\left(1.2 \times 10^{6}\right.$ cells/well) were incubated with ${ }^{35} \mathrm{~S}$-labeled reovirus $\left(10^{4}\right.$ viral particles/cell) for the period indicated, and the unbound virus was washed off with cold PBS five times. Each point represents the percentage of ${ }^{35} \mathrm{~S}$-labeled reovirus binding to the cells compared with the radioactivity of total inoculum to the well, and are expressed as mean \pm SD from two or three wells. 
tracellular cleavage of viral outer capsid proteins (cleavage of the $\mu$ lc protein to the $\delta$ protein and loss of the $\sigma 3$ protein) was observed beginning between 2 and $3 \mathrm{~h}$ of incubation in BAECs infected by T3D (Fig. 3) as well as by T1L (data not shown), indicating that a difference in proteolytic processing does not account for the difference in growth.

Northern blot analysis. To measure the amount of mRNA (plus strand) produced by T1L and T3D in the infected cells, we used cDNA for the T3D-S4 gene for the Northern blot analysis. We chose the $\mathrm{S} 4$ gene because it is one of the earlytranscribed genes whose transcription does not require synthesis of viral proteins and occurs at relatively high frequencies (for review, see reference 3 ) and because it exhibits $94 \%$ homology at the nucleotide level between T1L and T3D (20). We confirmed, using L cells, that the cDNA probe was hybridized with the S4-RNA of both T1L and T3D, although the signal of the T1L-S4-RNA is less strong than that of the T3DS4-RNA (Fig. 4). In contrast, the accumulation of S4-RNA in endothelial cells infected by T3D was much less than that in cells infected with T1L, 6 and $24 \mathrm{~h}$ after infection, in spite of the fact that the probe should have more homology with the S4 gene derived from T3D. To be certain that a difference in the S4 gene of T1L and T3D did not affect these results, we studied a reassortant virus (EB 68) that contained the M1 gene from T1L and the S4 gene from T3D. EB 68 grew like T1L in BAECs because of its T1L-M1 gene (Table I), and the production of the same gene could be compared between EB 68 and T3D, using the probe for the T3D-S4 gene. In EB 68 the $\mathrm{S} 4$ gene was extensively transcribed, similar to T1L (data not shown). Thus, these data suggested that $\mathrm{T} 3 \mathrm{D}$ has reduced accumulation of mRNA compared to T1L.

\section{Discussion}

In this report, we have found that the reovirus $\mathrm{M} 1$ gene is responsible for differences in the capacity of two reovirus strains to replicate in endothelial cells. This finding thus signifi-

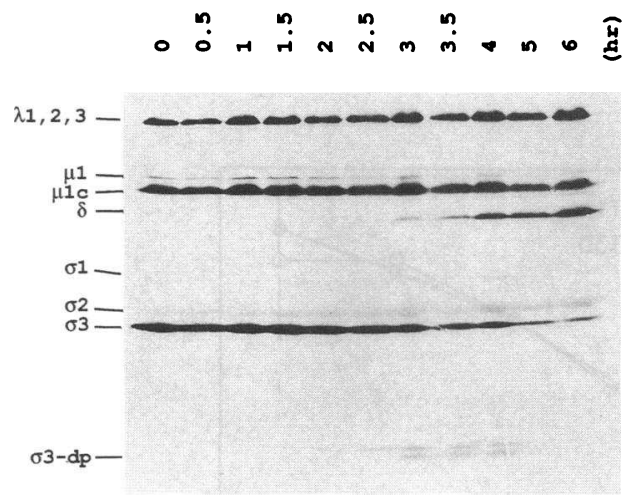

Figure 3. Processing of viral proteins in cultured BAECs infected by type 3 Dearing (T3D) reovirus. After adsorption of ${ }^{35} \mathrm{~S}$-labeled T3D reovirus $\left(10^{4}\right.$ viral particles/cell) to cells for $90 \mathrm{~min}$ at $4^{\circ} \mathrm{C}$, unbound virus was washed off, and cells were incubated with culture medium for the period indicated. Samples were prepared for SDS-PAGE, as described in Methods, and the fluorographed dried gel was exposed to film for autoradiography. Numbers at the top of each lane represent the time $(h)$ of incubation with culture medium; reovirus structural proteins or their derivatives are indicated at the left. $\sigma 3-\mathrm{dp}$ $=$ degradative product of the $\sigma 3$ protein.

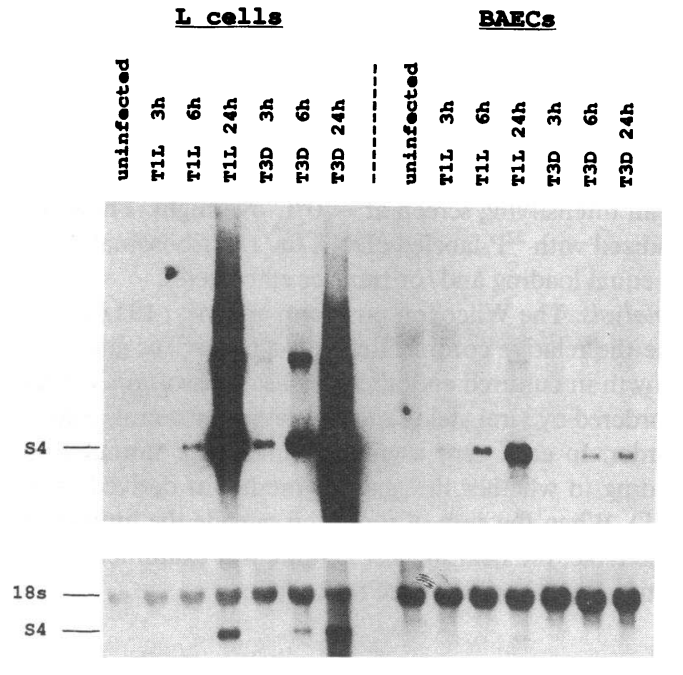

Figure 4. Northern blot analysis of viral mRNA in L cells and cultured BAECs infected by type 1 Lang (T1L) or type 3 Dearing (T3D) reovirus. Cells were infected at a multiplicity of infection of 10 and incubated for the period indicated. Total RNA was prepared and subjected to Northern blot analysis with ${ }^{32} \mathrm{P}$-labeled cDNA for the S4 gene of T3D and 18S-ribosomal RNA and autoradiographed, as described in Methods. Equal loading and/or transfer efficiencies between lanes (in L cells and BAECs) were confirmed by hybridization with 18S-cDNA, except the lane T3D-24 h in L cells, in which degradation of RNA was observed.

cantly extends our understanding of reovirus growth in different tissues. We have shown previously that the M1 gene also plays a role in growth in myocardial cells in culture (5) and in vivo in a myocarditis model in mice (6). The linkage of this viral M1 gene to cardiac and endothelial cells contrasts with the localization of virus in neurons $(21,22)$ and pituitary $(23)$ to the $\mathrm{S} 1$ gene, the extent of growth in the CNS to the M2 gene (24), inactivation of T3D in the GI tract to the $S 1$ gene (25), and growth in Peyer's patches to the S1 and L2 genes (25). Prior studies indicated that the $\mathrm{S} 1$ gene product, the $\sigma 1$ protein, is the cell attachment protein and functions at the level of binding to the cell surface $(26$; reviewed in 3,4$)$. The M2 protein is involved in processing the viral capsid and allowing the virus to interact with cell membranes (27). Thus, the role of the $\mathrm{S} 1$ and M2 gene products in allowing virus to bind and enter cells is clearly related to their function in viral growth in tissues. How the M1 gene product is responsible for allowing growth in endothelial cells and myocardial cells is not so clear.

It is clear that the M1 product ( $\mu 2)$ does not function at the earliest steps in virus-cell interactions. As seen in this study, there were no differences in binding or the early kinetics of viral capsid processing between T1L and T3D. The major difference seen was in the amount of viral mRNA as detected in the Northern blot analyses.

Synthesis of reovirus mRNA has been extensively studied in $\mathbf{L}$ cells (for reviews, see reference 3 ). Genetic studies have identified that the $\mathrm{L} 1$ gene determines the $\mathrm{pH}$ optimum of the transcriptase (28). Shatkin et al. (29) found that only four genes ( $\mathrm{L} 1, \mathrm{M} 3, \mathrm{~S} 3$, and S4) were transcribed in L cells in which the protein synthesis was inhibited by cycloheximide and that the transcription of the remaining six genes requires synthesis of one or more viral protein products of the early genes. In this study, we used cDNA for the S4 gene, one of the early genes, to 
examine the production of mRNA in BAECs, and found evidence consistent with the view that the production of T3DmRNA was significantly reduced in BAECs 6 and $24 \mathrm{~h}$ after infection.

We cannot state with absolute certainty that the signal we focused on came from mRNA (single-stranded [ss]) as opposed to the total viral particle containing double-stranded (ds) RNA. Definitive discrimination between these possibilities would require further experiments such as Northern hybridization of radiolabeled run-off transcripts of both, using a plasmid vector for in vitro transcription. However, the following findings indicated that the signal was likely from mRNA. As seen in Fig. 4, the signal from the S4 probe in L cells was intrinsically stronger in its interaction with T3D-S4-RNA than with T1L-S4-RNA. Thus, the stronger signal from T1L compared to T3D at 6 and $24 \mathrm{~h}$ in BAECs supports the concept that transcription is reduced in T3D. This cannot, of course, be stated with certainty since the probe would be expected to recognize the viral genome as well as S4 cDNA.

A preliminary experiment indicated that the production of mRNA in BAECs infected by T1L and by EB 68 was markedly inhibited by treatment of cells with cycloheximide at a concentration of $20 \mu \mathrm{g} / \mathrm{ml}$ (30; data not shown). This result implies that the $\mathrm{M} 1$ gene is not related to primary transcription but may be related to the events occurring between primary (from the parental genome) and secondary (from the progeny genome) transcription, for example, translation of reovirus mRNA, replication of viral ds-RNA, viral assembly, or transcription from the progeny ds-RNA genome. Further experiments are necessary to determine the role of the $\mathrm{M} 1$ gene in the reovirus replication cycle in BAECs and other cell types.

It is of interest that the M1 gene plays a role both in the growth of reovirus in cultured cardiac myocytes and in endothelial cells. Communication between cells in a paracrine or autocrine manner has become a field of interest recently, and evidence has accumulated indicating that such interactions exist between myocytes and endothelial cells $(31,32)$. In the case of viral myocarditis, the degree of myocardial necrosis correlates poorly with cardiac function (33), and paracrine products released from infected endothelial cells may aggravate myocardial dysfunction or injury in addition to direct viral damage of myocytes. TNF- $\alpha$, IL- 2 and IL- 6 are such paracrine cytokines causing negative inotropic effects on the heart, probably mediated at least in part by nitric oxide (34), although the enhanced production of these factors by infected endothelial cells has not yet been proved.

Reovirus is a well-characterized virus, allowing examination of the interaction between virus and endothelial cells because of the detailed information of its genetics and the relative ease with which its genome can be manipulated $(3,4)$. Verdin et al. (35) demonstrated that serotypes T1L and T3D of reovirus replicated in endothelial cells from the rat fat pad; they also identified a 54-kD protein as a putative cell surface receptor for both of these serotypes. In contrast to our results, they did not show a difference in growth between T1L and T3D, both serotypes replicating well in rat fat pad endothelial cells. This discrepancy might come from the heterogeneity of endothelial cells within the vasculature (large vessels or microvessels) as well as from different organs or species of animals used $(36,37)$.

Although acetylated LDL uptake is generally accepted as a marker, endothelial cells of different origin have diverse struc- tural and functional characteristics. Those from bovine aorta are among the best characterized, and most studies of viral infection of endothelial cells in vitro have been conducted using either BAECs or HUVECs $(1,38)$. As shown in Fig. $1 B$, we also examined the growth of reovirus in HUVECs with results similar to those in BAECs. Our in vitro results are supported by in vivo studies of Flamand et al. (39), who observed viral antigen in the endothelium of blood vessels in mice after infection with T1L but not with T3D.

An understanding of interactions between viruses and endothelial cells is necessary to elucidate the pathogenesis of viral infection, since viruses potentially gain access from the bloodstream to each organ through endothelial cells. Several viruses are known to replicate in endothelial cells and change their properties (for review, see reference 1). Dengue and Junin viruses, which are causes of hemorrhagic syndromes, have been reported to replicate in cultured endothelial cells (40). Herpes simplex virus (HSV) 1, poliovirus 1 , adenovirus 7 , and measles virus increased adhesion of granulocytes to infected endothelial cells (41). The production of CSF by endothelial cells was altered by infection with $\mathrm{HSV}-1$ and measles virus, and this alteration might contribute to changes in myelopoiesis that frequently accompany viral infection (42). Infection of bovine endothelial cells by HSV-1 reduced the synthesis of collagen and fibronectin (43). Accumulating evidence suggests that some viruses induce endothelial cell injury, which in turn may be associated with atherosclerosis (44).

While much recent effort has been directed to studies of responses of endothelial cells to infection, less information is available elucidating the interaction between viruses and endothelial cells. The experimental approach used in the studies reported here and the associated findings support the utility of this system for studies of the interaction between virus and endothelial cells at a molecular genetic level.

\section{Acknowledgments}

The authors thank Michael A. Gimbrone, Jr. for generously providing the endothelial cells and Michael Giantini for cDNA for the S4 gene of reovirus type 3. We thank Erin Smith, Jesse Keegan, Mary Anne Mann, and Elaine Freimont for their technical assistance, and Anula Jayasuriya, Max Nibert, Kenneth Tyler, and Greame Wilson for their thoughtful advice and helpful discussions.

This work was done during the tenure of a Research Fellowship from the American Heart Association, Massachusetts Affiliate, Inc. and was also supported by a Fellowship Grant from the Japan Heart Foundation and in part by NIH grants AI-73178, HL-36141, and HL42539. W. S. Colucci is a Sandoz Established Investigator of the American Heart Association.

\section{References}

1. Friedman, H. M. 1989. Infection of endothelial cells by common human viruses. Rev. Infect. Dis. 11:S700-704.

2. Sharpe, A. H., R. F. Ramig, T. A. Mustoe, and B. N. Fields. 1978. A genetic map of reovirus. I. Correlation of genome RNAs between serotypes 1, 2, and 3 . Virology. 84:63-74.

3. Schiff, L. A., and B. N. Fields. 1990. Reoviruses and their replication. In Virology. B. N. Fields, editor. Raven Press, Ltd., New York. 1275-1306.

4. Tyler, K. L., and B. N. Fields. 1990. Reoviruses. In Virology. B. N. Fields, editor. Raven Press, Ltd., New York. 1307-1328.

5. Matoba, Y., B. Sherry, B. N. Fields, and T. W. Smith. 1991. Identification of the viral gene responsible for growth of strains of reovirus in cultured mouse heart cells. J. Clin. Invest. 87:1628-1633.

6. Sherry, B., and B. N. Fields. 1989. The reovirus M1 gene, encoding a viral 
core protein, is associated with the myocarditic phenotype of a reovirus variant. J. Virol. 63:4850-4856.

7. Sherry, B., F. J. Schoen, E. Wenske, and B. N. Fields. 1989. Derivation and characterization of an efficiently myocarditic reovirus variant. J. Virol. 63:4840 4849.

8. Ramig, R. F., R. K. Cross, and B. N. Fields. 1977. Genome RNAs and polypeptides of reovirus serotypes 1, 2, and 3. J. Virol. 22:726-733.

9. Brown, E. G., M. L. Nibert, and B. N. Fields. 1983. The L2 gene of reovirus serotype 3 controls the capacity to interfere, accumulate deletions, and establish persistent infection. In Double-Stranded RNA Viruses. R. W. Compans, and D. H. L. Bishop, editors. Elsevier Science Publishing, Inc., New York. 275-287.

10. Gimbrone, M. A., Jr. 1976. Culture of vascular endothelium. In Progress in Hemostasis and Thrombosis. Vol. 3. T. H. Spaet, editor. Grune and Stratton, Inc., New York. 1-28.

11. Davies, P. F., H. G. Rennke, and R. S. Cotran. 1981. Influence of molecular charge upon the endocytosis and intracellular fate of peroxidase activity in cultured arterial endothelium. J. Cell. Sci. 49:69-86.

12. Virgin, H. W. IV, R. Bawwel-Duby, B. N. Fields, and K. L. Tyler. 1988. Antibody protects against lethal infection with the neurally spreading reovirus type 3 (Dearing). J. Virol. 62:4594-4604.

13. Sturzenbecker, L. J., M. Nibert, D. Furlong, and B. N. Fields. 1987. Intracellular digestion of reovirus particles requires a low $\mathrm{pH}$ and is an essential step in the viral infectious cycle. J. Virol. 61:2351-2361.

14. Drayna, D., and B. N. Fields. 1982. Genetic studies on the mechanism of chemical and physical inactivation of reovirus. J. Gen. Virol. 63:149-159.

15. Chirgwin, J. M., A. E. Przybyla, R. J. MacDonald, and W. J. Rutter. 1979. Isolation of biologically active ribonucleic acid from sources enriched in ribonuclease. Biochemistry. 18:5294-5299.

16. Giantini, M., L. S. Seliger, Y. Furuichi, and A. J. Shatkin. 1984. Reovirus type 3 genome segment S4: nucleotide sequence of the gene encoding a major virion surface protein. J. Virol. 52:984-987.

17. Feinberg, A. P., and B. Vogelstein. 1983. A technique for radiolabelling RNA restriction fragments to high specific activity. Anal. Biochem. 132:6-13.

18. Lee, R. T., K. D. Bloch, J. M. Pfeffer, E. J. Neer, and C. E. Seidman. 1988 Atrial natriuretic gene expression in ventricles of rats with spontaneous biventricular hypertrophy. J. Clin. Invest. 81:431-434.

19. Lentner, C., Editor. 1982. Geigy Scientific Tables. Vol. 2. Introduction to Statics. Ciba-Geigy Corp., West Caldwell, NJ. 152-162.

20. Atwater, J. A., S. M. Munemitsu, and C. E. Samuel. 1986. Biosynthesis of reovirus-specified polypeptides; molecular cloning and nucleotide sequence of the reovirus serotype 1 Lang strain S4 mRNA which encodes the major capsid surface polypeptide $\sigma 3$. Biochem. Biophys. Res. Commun. 136:183-192.

21. Weiner, H. L., M. L. Powers, and B. N. Fields. 1980. Absolute linkage of virulence and central nervous system cell tropism of reoviruses to viral hemagglutinin. J. Infect. Dis. 141:609-616.

22. Dichter, M. A., and H. L. Weiner. 1984. Infection of neuronal cell cultures with reovirus mimics in vitro patterns of neurotropism. Ann. Neurol. 16:603610.

23. Onodera, T., A. Toniolo, U. R. Ray, A. B. Jensen, R. A. Knazek, and A. L. Notkins. 1981. Virus-induced diabetes mellitus. XX. Polyendocrinopathy and autoimmunity. J. Exp. Med. 153:1457-1473.

24. Hrdy, D. B., D. N. Rubin, and B. N. Fields. 1982. Molecular basis of reovirus neurovirulence: role of the M2 gene in avirulence. Proc. Natl. Acad. Sci. USA. 79:1298-1302.
25. Bodkin, D. K., and B. N. Fields. 1989. Growth and survival of reovirus in intestinal tissue; role of the L2 and S1 genes. J. Virol. 63:1188-1193.

26. Weiner, H. L., K. A. Ault, and B. N. Fields. 1980. Interactions of reovirus with cell surface receptors. I. Murine and human lymphocytes have a receptor for the hemagglutinin of reovirus type 3. J. Immunol. 124:2143-2148.

27. Drayna, D., and B. N. Fields. 1982. Genetic studies on the mechanisms of chemical and physical inactivation of reovirus. J. Gen. Virol. 63:149-159.

28. Drayna, D., and B. N. Fields. 1982. Activation and characterization of the reovirus transcriptase; genetic analysis. J. Virol. 41:110-118.

29. Shatkin, A. J., and A. J. LaFiandra. 1972. Transcription by infectious subviral particles of reovirus. J. Virol. 10:698-706.

30. Watanabe, Y., S. Milliward, and A. F. Graham. 1968. Regulation of transcription of the reovirus genome. J. Mol. Biol. 36:107-123.

31. Re, R. N. 1989. The cellular biology of angiotensin; paracrine, autocrine, and intracrine actions in cardiovascular tissues. J. Mol. Cell. Cardiol. 21(V):6369.

32. Shubeita, H. E., P. M. McDonough, A. N. Harris, K. U. Knowlton, C. C. Glembotski, J. H. Brown, and K. R. Chien. 1990. Endothelin induction of inositol phospholipid hydrolysis, sarcomere assembly, and cardiac gene expression in ventricular myocytes. J. Biol. Chem. 265:20555-20562.

33. Dec, G. W. Jr., I. F. Palacios, J. T. Fallon, H. T. Aretz, J. Mills, D. C.-S Lee, and R. A. Johnson. 1985. Active myocarditis in the spectrum of acute dilated cardiomyopathies; clinical features, histologic correlates, and clinical outcome. N. Engl. J. Med. 312:885-890.

34. Finkel, M. S., C. V. Oddis, T. D. Jacob, S. C. Watkins, B. G. Hattler, and R. L. Simmons. 1982. Negative inotropic effects of cytokines on the heart mediated by nitric oxide. Science (Wash. DC). 257:387-389.

35. Verdin, E. M., G. L. King, and E. Maratos-Flier. 1989. Characterization of a common high-affinity receptor for reovirus serotypes 1 and 3 on endothelia cells. J. Virol. 63:1318-1325.

36. Gerritsen, M. E. 1987. Functional heterogeneity of vascular endothelial cells. Biochem. Pharmacol. 36:2701-2711.

37. Kumar, S., D. C. West, and A. Ager. 1987. Heterogeneity in endothelial cells from large vessels and microvessels. Differentiation. 36:57-70.

38. Etingin, O. R., R. L. Silverstein, H. M. Friedman, and D. P. Hajjar. 1990. Viral activation of the coagulation cascade; molecular interactions at the surface of infected endothelial cells. Cell. 61:657-662.

39. Flamand, A., J.-P. Gagner, L. A. Morrison, and B. N. Fields. 1991. Penetration of the nervous system of suckling mice by mammalian reoviruses. $J$ Virol. 65:123-131.

40. Andrews, B. S., A. N. Theofilopoulos, C. J. Peters, D. J. Loskkutoff, W. E. Brandt, and F. J. Dixon. 1978. Replication of Dengue and Junin viruses in cultured rabbit and human endothelial cells. Infect. Immun. 20:776-781.

41. MacGregor, R. R., H. M. Friedman, E. J. Macarak, and N. A. Kefalides. 1980. Virus infection of endothelial cells increases granulocyte adherence. $J$. Clin. Invest. 65:1469-1477.

42. Gerson, S. L., H. M. Friedman, and D. B. Cines. 1985. Viral infection of vascular endothelial cells alters production of colony-stimulating activity. J. Clin. Invest. 76:1382-1390.

43. Macarak, E. J., H. M. Friedman, and N. A. Kefalides. 1985. Herpes simplex virus type 1 infection of endothelium reduces collagen and fibronectin synthesis. Lab. Invest. 53:280-286.

44. Cunningham, M. J., and R. C. Pasternak. 1988. The potential role of viruses in the pathogenesis of atherosclerosis. Circulation. 77:964-966. 